\title{
O CICLO DO PLANEJAMENTO MUNICIPAL: DO PROGRAMA DE GOVERNO AO ORÇAMENTO
}

\section{ARTIGO ORIGINAL}

JÚNIOR, Marcos de Oliveira Alves ${ }^{1}$

JúNIOR, Marcos de Oliveira Alves. O Ciclo do Planejamento Municipal: Do Programa de Governo ao orçamento. Revista Científica Multidisciplinar Núcleo do Conhecimento. Ano 05, Ed. 09, Vol. 08, pp. 36-45. Setembro de 2020. ISSN: 24480959, Link de

acesso: https://www.nucleodoconhecimento.com.br/administracao/ciclo-doplanejamento

\section{RESUMO}

O planejamento é essencial em qualquer área da vida, na administração pública não seria diferente, contudo, principalmente quando se trata de administração pública municipal, percebe-se a fragilidade dessa ação basilar para uma boa gestão. $\mathrm{O}$ ditado popular que todos conhecemos "prevenir é melhor que remediar" é muito utilizado e de significado simples e objetivo, remetendo sempre a ações de prevenção, na administração pública é possível vislumbramos um novo ditado "planejar é melhor do que remediar". É justamente no planejamento na administração pública municipal que o presente artigo irá focar, buscando respostas para que os gestores e sua equipe entendam a importância e alcancem o tão sonhado planejamento. Qual a importância do Planejamento na Administração Pública? No intuito de responder ao problema, tem-se como objetivo geral: analisar as contribuições do Planejamento prévio, do plano de Governo ao Orçamento. O método dedutivo foi o adotado para a efetivação desta pesquisa. Tratou-se de uma pesquisa exploratória; quanto à abordagem do problema, foi qualitativa; quanto aos procedimentos técnicos, foi bibliográfica. O

1 Pós-Graduado em Administração Pública Municipal, Pós-Graduado em Contabilidade Pública Municipal, Bacharel em Ciências Contábeis. 
Planejamento na Gestão Pública torna-se a cada dia mais essencial e imprescindível para se atingir a finalidade precípua da administração que é o bem-estar social, contudo, quando esse planejamento está relacionado a Gestão Pública, percebe-se a ausência de sistematização, ficando restrito aos planejamentos orçamentários previstos na legislação, realizados de forma mecanizada, sem a preocupação de construir com objetivos traçados, uma problemática delineada, e sem a participação dos envolvidos na forma devida.

Palavras-chave: Planejamento, Administração Pública, gestores.

\section{INTRODUÇÃO}

O presente artigo foi elaborado com base na experiência do autor, onde ao longo dos 18 (dezoito) anos atuando com contabilidade pública vivenciou os reflexos do planejamento municipal e ou ausência do mesmo. Deste modo, o objetivo do artigo é evidenciar à importância e as vantagens do planejamento para uma gestão municipal de excelência, apresentando quando se deve iniciar esse planejamento, alguns pontos indispensáveis no processo, e o ciclo recomendado para se alcançar os objetivos de forma planejada.

Nessa linha, ao oferecer elementos para o aperfeiçoamento da discussão sobre planejamento na gestão municipal, este estudo pretende contribuir com a consolidação do planejamento prévio, disseminando a importância dessa ferramenta para à gestão e para toda a sociedade, bem como as consequências da sua ausência. Segundo Rezende (2008, p.15) "planejar é sinônimo de objetivar, pensar, sonhar, desejar, e etc (...)".

Se destaca a importância da implantação do planejamento prévio, e da constante revisão desses planos, somente com este tipo de instrumento que a Gestão começará a galgar maior participação em suas ações e melhores resultados para a sociedade. 


\section{QUANDO INICIAR UM BOM PLANEJAMENTO NA ADMINISTRAÇÃO PÚBLICA?}

Uma gestão municipal de sucesso indispensavelmente se inicia com um bom planejamento, é certo que esse planejamento tem um início palpável, mesmo que muito genérico, na construção do plano de governo a ser entregue à justiça eleitoral quando do registro da candidatura (Nova redação do art. 11, § 1ㅇ, IX, da Lei 9.504/97). Nesse momento o então candidato, tem a possibilidade de planejar e colocar suas ideias de governança para o seu município no papel, tem a possibilidade de se debruçar e esmiuçar a história, dados, fatos, possibilidades, estatísticas e a realidade atual do seu município e claro dos munícipes. Contudo, raros os candidatos que se aprofundam em um plano de governo bem elaborado, bem planejado, com um estudo detalhado e resultado de um trabalho em equipe, de pessoas que tenham mínimo entendimento nas diversas áreas no qual o plano deve abranger.

É sabido que essa obrigatoriedade é um tanto quanto recente, mais antes de tal, os candidatos já utilizavam esse mecanismo de "planejamento" para nortear sua campanha eleitoral, mesmo que fossem rascunhos estratégicos de campanha. $\mathrm{Na}$ maioria das vezes os planos de governo entregues ao eleitoral são simplesmente para cumprir uma obrigação, um pré-requisito para o registro da candidatura, em outras tantas vezes, são elaborados por profissionais do marketing político, que geralmente pouco conhecem a realidade local e desenvolvem uma peça muito vistosa, linda, empolgante, contudo, bem distante da realidade local, quase impraticável.

A alteração na legislação eleitoral citada (Nova redação do art. 11, § 1ำ IX, da Lei 9.504/97), não traz a previsão de punições aos que descumprirem suas propostas e promessas, mas pode representar um importante avanço no sentido da conscientização e da crítica por parte dos eleitores, traz consigo uma "obrigação" moral para com o eleitorado. O professor de direito eleitoral Alberto Rollo (entrevista ao site Gazeta Digital em 15/05/2010) destaca:

O dispositivo incluído é interessante porque gera uma pena moral, qual seja, ter uma agenda a cumprir que, caso não atingida, poderá gerar 
críticas ao descumpridor, aclarando aspectos morais do descumprimento, ou pode gerar críticas às propostas por entendê-las insuficientes (GAZETA, 2010)

Qual seria então o modelo ideal de planejamento pré-eleitoral? A resposta está nas necessidades de cada município, um candidato que pretende pautar sua administração em planejamento prévio, deve primeiramente cercar-se de bons assessores, de pessoas que conheçam a realidade local e possam alinhar isso aos ideais políticos e a capacidade econômica do Município. Um estudo bem feito, amplo e detalhado dará ao então candidato e sua equipe de campanha um diagnóstico prévio da real situação, isso possibilita ao futuro gestor saber "onde está pisando". Para Saldanha (2006, p.23) "o propósito do planejamento Governamental é definir objetivos para o futuro e os meios para alcança-los".

\section{O PLANEJAMENTO PÓS ELEIÇÃO}

candidato foi eleito, e agora qual o caminho a seguir? Esse segundo momento é talvez o mais importante no planejamento de uma gestão, e muitos gestores eleitos acabam não se dando conta dessa importância. É nesse momento que o gestor e sua equipe devem revisar o seu plano de governo, se aprofundar agora de forma minuciosa em cada área de atuação, conhecer a realidade da gestão atual a qual irá suceder, perguntas como: Qual o endividamento bruto do meu município? Qual o índice atual de gastos com pessoal e encargos sociais? Qual o quadro de efetivos do Município? Como é feita a limpeza pública? Os contratos de serviços continuados serão aditivados? O que deve ser preparado para que dia 01/01 não se tenha problemas com a saúde, a segurança, a limpeza urbana? Dentre muitas outras perguntas que devem ter suas respostas adquiridas o quanto antes, e isso possibilitará um bom planejamento para a gestão vindoura.

Existe a obrigatoriedade de transição de governo (Partindo da experiência Federal regulada pela Lei no 10.609, de 20 de dezembro de 2002, e pelo Decreto № 4.298, de 11 de julho de 2002, motivados pelas propostas do Comitê de Articulação Federativa - CAF, consolidadas na Agenda Nacional de Apoio à Gestão dos Municípios; atualmente os Tribunais de Contas dispõem de resoluções especificas para transição 
de governo), porém, sabemos que a maturidade dos governantes e muitas vezes da maioria de sua equipe e eleitorado não é suficiente para esse ato de democracia e continuidade da administração, o que temos pós eleição geralmente são atitudes totalmente contrarias a uma boa transição, com ações que dificultam o conhecimento da realidade, que por vezes resulta em atos de improbidade administrativa, de crime contra a coisa pública, e trarão prejuízos muitas vezes incalculáveis a nova gestão e principalmente à população. Não são raros os casos em que simplesmente não há transição, nem mesmo a formalização da burocracia documental definida pela legislação vigente, simplesmente, se torna um "pós-guerra" onde se o meu inimigo venceu essa batalha, dificultarei totalmente sua atuação posterior, assim, poderei vencer a próxima peleja; mais e o povo? o povo "esquece fácil" assim é a imagem que muitos políticos/gestores tem. Conforme afirma Meirelles (2014, p.843) " a finalidade precípua da administração é a promoção do bem-estar social".

Considerando que a transição de governo quando bem feita, possibilita o conhecimento prévio da real situação municipal, seus potenciais, as coisas boas da gestão que está deixando o governo e podem ter uma continuidade, afinal de contas são boas ações, e isso parece obvio já que a administração pública deve seguir o princípio da continuidade, porém, não raros os casos em que um projeto é descontinuado pelo simples fato de ter sido implantado pela outra gestão. Na transição é indispensável uma verificação geral e pormenorizada de todos os setores administrativos, uma profundidade de detalhes que possibilite saber se os servidores efetivos existentes no quadro do município são capazes de desenvolver as demandas do setor ao qual está lotado, se setores primordiais como: Contabilidade, $\mathrm{RH}$, Licitação e Tributos, dispõe de servidores capacitados para exercer as funções, e o quanto da engrenagem administrativa é movimentada por comissionados, esse diagnóstico dará uma visão das necessidades de pessoal, de profissionais qualificados, ou mesmo da contratação de assessorias especificas para cada demanda.

O momento da transição também remete a uma grande necessidade de definição por parte do futuro gestor, a definição da sua equipe de trabalho, dos cargos de confiança, do secretariado, tais definições são extremamente importantes para o planejamento. 
É plausível por exemplo que o futuro secretário de Saúde já participe da transição de governo, terá seu olhar e foco específico para sua pasta, necessidades estruturais e de equipe, situação atual e a desejada, todos esses diagnósticos e paralelos irão moldar um bom planejamento alavancando a possibilidade de sucesso, e o exemplo do secretário de saúde se expande a todas as demais pastas. Essa equipe a ser formada pelo novo gestor deverá ter ao menos um equilíbrio entre políticos e técnicos, não há gestão sem uma visão política, mais é certo que uma gestão sem uma visão técnica estará fadada a grandes problemas de planejamento e consequentemente de execução, o que acarretará em problemas até de cunho pessoal ao futuro gestor. A legislação (Constituição Federal de 1988) permite cargos de provimento em comissão, os chamados de livre nomeação e exoneração, destinando-se às atribuições de direção, chefia e assessoramento, contudo, deve observar a proporcionalidade em relação as funções efetivas de provimento por meio de concurso público.

Conhecer a realidade municipal de forma detalhada ajudará na decisão de formação da equipe, dando melhor base para saber qual área se deve inserir pessoas extremamente técnicas? onde demanda pessoas com maior foco político? onde cabe o meio termo? Há ainda uma grande problemática na maioria dos municípios de pequeno porte, simplesmente a escassez de técnicos com bom conhecimento e experiência nas áreas necessárias, a famosa mão de obra qualificada, e isso é um grande problema. As consequências dessa escassez são geralmente 0 preenchimento das vagas com pessoas sem a capacidade e conhecimento necessários, ocupando tais cargos simplesmente por "compromisso político", e esse sem dúvidas é um dos maiores vilões da administração pública, e o primeiro passo para o fracasso no planejamento da gestão.

O planejamento na visão de Oliveira (2012, p.41) é:

(...) a metodologia administrativa que permite diagnosticar e analisar situações atuais, de estabelecer resultados, objetivos e metas a serem alcançadas pelas organizações e de delinear ações - estratégias - para alcançar esses resultados, bem como estabelecer leis e normas políticas que servem de sustentação a esse procedimento administrativo. 
Deste modo, quando do processo de transição, se a equipe do novo governo se deparar com dificuldades na obtenção dos dados, dificuldade em ter acesso aos setores públicos e impedimento em debater com os servidores municipais, é indispensável se tomar as medidas legais, o prejuízo de uma transição fragilizada e incompleta pode ser enorme para a nova gestão, sempre partindo do pressuposto de planejamento prévio e detalhado das necessidades e ações do governo.

\section{PRIMEIRO ANO DE MANDATO, CONTININUIDADE OU RENOVAÇÃO TOTAL?}

Temos agora um terceiro momento, o primeiro ano da nova gestão, momento esse onde se coloca à prova o planejamento prévio que foi feito ou a ausência deste. Indispensável citarmos novamente, que a administração pública deve seguir o princípio da continuidade, logo, mesmo se tratando de uma nova gestão há "amarrações" legais que não são opcionais, a obrigatoriedade dessa continuidade é materializada nos instrumentos constitucionais de planejamento e orçamento (Plano Plurianual - PPA, Lei de Diretrizes Orçamentárias - LDO e Lei Orçamentária Anual LOA), sendo o PPA - Plano Plurianual, elaborado no primeiro ano de gestão para viger até o primeiro ano da próxima gestão, ordenamento esse claro e especifico com a finalidade de se manter uma continuidade na gestão pública e em suas ações, em seguida temos a LDO - Lei de Diretrizes Orçamentárias e LOA - Lei Orçamentária Anual, ambas aprovadas em um exercício para vigorar no próximo, ou seja, temos duas leis de suma importância para o planejamento aprovadas no último ano de uma gestão para vigerem no primeiro ano da próxima gestão, volto a bater na tecla da ideia constitucional de continuidade, porém, na pratica os municípios e seus gestores tem muitas dificuldades em transformar as peças documentais em uma realidade de planejamento e execução continuados e as peças de planejamento e diretrizes orçamentária, acabam nem sendo utilizadas como subsídio para elaboração dos Planos Municipais de cada Secretaria, tornando-as obsoletas.

É bastante comum nos depararmos no primeiro ano de mandato com orçamentos muito mal feitos, seja pela deficiência técnica das equipes de planejamento dos 
municípios, seja pelo fenômeno do "quanto pior, melhor" aplicado muitas vezes pelos gestores que estão deixando o mandato, e imaginam que prejudicar a próxima gestão é o melhor caminho para retornar ao poder. Temos então um primeiro ano de gestão entrelaçado a um planejamento orçamentário definido pela gestão anterior, ligado ao PPA confeccionado há 5 anos atrás, e se tudo isso for somado a um planejamento prévio mau feito pela nova gestão, ou mesmo à ausência desse planejamento prévio, a tendência é de um resultado desastroso, todavia, se todo esse processo foi analisado previamente, planejado e estudado, se minimiza a margem de erros, se projeta necessidades e carências, e a busca por soluções é otimizada.

O principal benefício do planejamento é o estabelecimento de um futuro curso de ação que promova a coordenação dos recursos internos dá organização com seus desafios políticos e externos. O processo de planejamento integra as funções da organização com seus recursos voltados para a finalidade de alcançar seus objetivos (SORD e WEISCH, 1964).

O primeiro ano de gestão trará sempre muitas experiências para o novo gestor e sua equipe, muitas delas serão negativas outras tantas positivas, de sorte que todos aqueles que aprendem com os erros e tem a sabedoria de buscar evitá-los e prevenilos, galgam o caminho do planejamento para alcançar o êxito. Finalizado o primeiro ano de uma nova gestão é indispensável que o gestor reúna sua equipe e solicite de todas as secretarias e setores técnicos um relato sobre a situação encontrada no início da gestão, o que foi feito durante $o$ ano, as dificuldades, as soluções e principalmente o planejamento para que no segundo ano o resultado seja melhor. Daí se aplica a necessidade do Relatório de Gestão que possibilita ao Gestor Municipal e Secretários uma análise da implementação das políticas públicas, das metas previstas e alcançadas e das considerações a serem apontadas para que o município consiga atingir os seus indicadores e metas, no ano seguinte.

\section{HÁ TEMPO PARA CORRIGIR O RUMO DA GESTÃO?}

A resposta para essa pergunta é simples: depende. Porém faze-lo não é algo tão simplório, afinal de contas "planejar é melhor do que remediar", para se corrigir os 
rumos depende da vontade e percepção do gestor, depende da capacidade de sua equipe, e depende do quanto a ausência de planejamento anterior comprometeu às ações futuras.

É plenamente possível se construir um orçamento bem feito, discutido e bem projetado, na medida certa para o município, e assim ter um segundo ano de gestão nos moldes necessários a nível orçamentário, como também é plenamente possível se construir um planejamento financeiro adequado à realidade do município e executá-lo no segundo ano da gestão, por outro lado, existem resquícios da ausência de planejamento prévio que podem demandar um esforço muito maior para adequação, podemos citar o índice de gastos com pessoal, onde no primeiro ano de gestão é pouco observado por muitos gestores que acabam inflando a folha e tornam os recursos dos municípios praticamente reféns da folha de pagamento e seus encargos (E o INSS - Instituto Nacional de Seguridade Social? Merece uma pauta específica, que ficará para outra oportunidade) e para se reconduzir o índice aos limites prudências da LRF - Lei de Responsabilidade Fiscal, é um caminho árduo e bem complicado, outros exemplos são as licitações e os convênios, principalmente quando se tratar de recursos federais, em ambos os casos as consequências para gestão e principalmente para o gestor são terríveis, são incontáveis os casos de gestores que tiveram problemas com devolução de recursos, multas, bloqueios de bens, tudo fruto de falta de prestação de contas, execução errada ou incompleta dos convênios, licitações totalmente mal feitas, e tudo isso reflexo da falta de planejamento.

O segundo ano de gestão é oportuno para "remediar", a nova equipe já estará mais experiente, terá vivido todo um exercício, passado pelas mais diversas situações, e terá totais condições de buscar um melhor planejamento e soluções para as problemáticas apresentadas em cada área. Defendo inclusive uma tese de que deveria haver uma mudança quanto ao ano de elaboração do PPA - Plano Plurianual, a realidade de maturidade e condições técnicas dos municípios de menor porte é de um primeiro ano de gestão de muito aprendizado e dificuldades, momento esse em que não se reúnem as condições necessárias para se elaborar um planejamento tão 
importante e que vigorará para os próximos 4 (quatro) anos do Município, ou seja, planejarei a longo prazo sem conhecer direito meu município e todas as anuências necessárias, por que não definir essa obrigatoriedade para o segundo ano de mandato? A resposta também é simples, a legislação em sua perfeita combinação de instrumentos, trata do mundo ideal, mais nós temos um "mundo real" onde a realidade é totalmente diferente, eu penso que isso deveria ser levado em conta.

Sem o conhecimento de um futuro curso planejado de ações e eventos, os administradores não têm base para decisões. O sucesso na implementação de planos está constantemente ameaçado por problemas de controle organizacional, pelo comportamento dos funcionários na organização e pela tendência geral desta a resistir a mudanças (GORDON, 1992).

Cada novo ano é também um novo ciclo na gestão, sendo possível efetuar muitas correções e ajustes, basta planejar e executar, nunca é tarde, porém "remediar" não garante que não ficarão cicatrizes.

\section{CONCLUSÃO}

O caminho para o sucesso na administração pública passa inevitavelmente por um planejamento bem feito, planejamento esse que deve se iniciar ainda na confecção do plano de governo, se intensificando após as eleições, se materializando na transição de governo e se consolidando no início da gestão, esse é o modelo que entendemos ideal, que possibilitará aos gestores e sua equipe trabalharem com maior lucidez, executarem com a certeza de um planejamento sólido, não esquecendo que cada ano de uma gestão é um ciclo que se renova, possibilitando sempre "remediar" corrigindo o rumo das coisas. Aos que não foram felizes em todo esse ciclo de planejamentos, ou simplesmente não o fizeram em tempo algum, se há um momento ideal nesse cenário para se corrigir os rumos, é o segundo ano de mandato, aprender com os erros e mudar as coisas, é preciso saber onde se quer chegar, o escritor Lewis Carroll já dizia "Se você não sabe onde quer ir, qualquer caminho serve" (Livro Alice no País das Maravilhas), é preciso ter a convicção de qual gestão se quer ter, definido isso é partir para o planejamento e nunca esquecer: "planejar é melhor que remediar". 


\section{REFERÊNCIAS}

BRASIL. Lei ํํ 10.609, de 20 de dezembro de 2002 - Dispõe sobre a instituição de equipe de transição. Disponível em: www.planalto.gov.br

BRASIL. Constituição (1988). Constituição da República Federativa do Brasil. Disponível em: www.planalto.gov.br.

BRASIL. Lei Complementar n.․ 101, de 04 de maio de 2000. Estabelece normas de finanças públicas voltadas para a responsabilidade na gestão fiscal e dá outras providências. Disponível em: www.planalto.gov.br.

BRASIL. Lei no 9.504/97 - Lei Das Eleições. Disponível em: www.tse.jus.br

REZENDE, Denis Alcides, Planejamento estratégico para organizações privadas e públicas: Guia prático para elaboração do projeto de plano de negócios. Rio de Janeiro. Brasport, 2008.

OLIVEIRA, Djalma de Pinho Rebouças de. Teoria Geral da Administração: uma abordagem prática. 3 ed. São Paulo. Atlas, 2012.

MEIRELLES, Hely Lopes. Direito Administrativo Brasileiro. 40. Ed. São Paulo. Malheiros Editores, 2014.

SALDANHA, Clezio. Introdução à gestão pública. 2 ed. São Paulo. Saraiva, 2006.

Enviado: Agosto, 2020.

Aprovado: Setembro, 2020. 